\title{
Effects of budlein A on human neutrophils and lymphocytes
}

\author{
Carollinie Dias KNOB ${ }^{1 *}$, Milena da SILVA ${ }^{*}$, Thaís Helena GASPAROTO'1, Carine Ervolino de OLIVEIRA ${ }^{1}$, Nádia Ghinelli \\ AMÔR ${ }^{1}$, Nilton Syogo ARAKAWA ${ }^{2}$, Fernando Batista da COSTA $^{3}$, Ana Paula CAMPANELLI ${ }^{1}$
}

1- Universidade de São Paulo, Faculdade de Odontologia de Bauru, Departamento de Ciências Biológicas, Bauru, SP, Brasil.
2- Universidade Estadual de Londrina, Londrina, PR, Brasil.
3- Universidade de São Paulo, Faculdade de Ciências Farmacêuticas de Ribeirão Preto, Departamento de Farmacognosia, Ribeirão Preto, SP, Brasil.

*Both authors have equally collaborated in this investigation.

Corresponding address: Ana Paula Campanelli - Departamento de Ciências Biológicas - Faculdade de Odontologia de Bauru - Universidade de São Paulo - Al. Octávio Pinheiro Brisolla, 9-75 - 17012-901 - Bauru - São Paulo - Brazil - Phone +55 1432358271 - Fax: 551432358271 - e-mail: apcampan@usp.br

Submitted: November 26, 2015 - Accepted: January 27, 2016

\section{ABSTRACT}

\begin{abstract}
Sesquiterpene lactones (SLs) are the active constituents of a variety of medicinal plants $S$ used in traditional medicine for the treatment of inflammatory diseases and other ailments. Objective: In this study, we evaluated whether budlein A modulates the activation of innate and adaptive immune cells such as neutrophils and lymphocytes. Material and Methods: Our research group has investigated several plant species and several compounds have been isolated, identified, and their medical potential evaluated. Budlein A is a SL isolated from the species Aldama buddlejiformis and A. robusta (Asteraceae) and shows anti-inflammatory and anti-nociceptive activities. Advances in understanding how plantderived substances modulate the activation of innate and adaptive immune cells have led to the development of new therapies for human diseases. Results: Budlein A inhibited MPO activity, IL-6, CXCL8, IL-10, and IL-12 production and induces neutrophil apoptosis. In contrast, budlein A inhibited lymphocyte proliferation and IL-2, IL-10, TGF- $\beta$, and IFN- $\gamma$ production, but it did not lead to cell death. Conclusions: Collectively, our results indicate that budlein A shows distinct immunomodulatory effects on immune cells.
\end{abstract}

Keywords: Lactones. Neutrophils. Lymphocytes.

\section{NTRODUCTI ON}

The ability of the immune system to respond to a variety of stimuli is central to its function in pathogen clearance and tissue repair ${ }^{4}$. The immune homeostasis and control of inflammation in different pathological settings is maintained by the balance between pro- and anti-inflammatory signaling ${ }^{6}$, and most research has focused on understanding the mechanisms that regulate the immune response $4,6,8,9$. New therapeutic agents are currently under investigation for pathological conditions in which the balance between activation and suppression of the immune response has failed $^{6}$. Studies have shown that plant-derived compounds have immunomodulatory effects without direct immunosuppressive action such as clinically used corticosteroids $2,3,16,27$. However, the mere isolation of new naturally-occurring antiinflammatory agents does not necessarily lead to a drug until the exact mechanism of action and their possible toxic effects are completely determined ${ }^{9}$. Moreover, many biologically active compounds that do not afford a new drug or even a principal compound can be used as prototypes for the study of the mechanisms involved in a certain biological effect. Budlein $A$, a sesquiterpene lactone ( $S L$ ) formerly isolated from the Central American species Aldama buddlejiformis (DC) ${ }^{1}$ and more recently from the South American A. robusta Gardner (Asteraceae), has been described as presenting anti-inflammatory activity ${ }^{1,7,27}$. Recent studies have shown its anti-nociceptive and anti-inflammatory activities in mice 22,27 . Although this information is important for determining its properties, it provides restricted parameters about how this compound 
affects other cells, adaptive immune response and $\mathrm{T}$ cell compartment. An immunomodulatory substance might show antibacterial activity, but the induced cell death could also be harmful to immune responses, pathogen clearance and tissue repair ${ }^{11,18}$. In this context, research to develop new anti-inflammatory agents to control the damage and exacerbated inflammation mediated, in part, by lymphocyte activation, has been stimulated. Given the broad information relating SLs and immunomodulation, we should evaluate whether budlein A modulates the activation of innate and adaptive immune cells.

\section{MATERI AL AND METHODS}

\section{Budlein A}

Budlein A ( $M W=374.1365)$ was isolated from the leaves of Viguiera robusta, as previously described $^{27}$. Its chemical structure was determined by means of spectrometric analysis, i.e., IR, $1 \mathrm{H}$, and $13 \mathrm{C}$ nuclear magnetic resonance (NMR) spectrometry as well as comparison with an authentic sample and data reported in literature ${ }^{5}$. Analytical procedures using spectroscopy and chromatographic techniques indicated that the purity of budlein $A$ used in this study ranged between $95-98 \%$. Prior to the bioassays, budlein A was dissolved in dimethylsulfoxide (DMSO) (SIGMA - St. Louis, MO, USA) (0.1\% in RPMI 1640 medium - GIBCO - Grand Island, NY, USA).

\section{Healthy volunteers}

We used peripheral blood from 30 healthy volunteers (17 men and 13 women; age ranged between 27-50 years). All subjects had no active diseases at the time of phlebotomy. All subjects signed an informed consent releasing the use of blood for research purposes approved by the Bauru School of Dentistry, University of São Paulo.

\section{I solation of leukocytes}

Peripheral blood was harvested with heparin (50 U/ml) from healthy subjects. Both groups of leukocytes were layered over two different density Histopaque gradients (SIGMA) and centrifuged for $30 \mathrm{~min}$ at $450 \mathrm{X} \mathrm{g}$. Peripheral blood mononuclear cells (PBMC) were obtained from the first layer (onto Histopaque 1077) and neutrophils were isolated from the second buffy coat layer (onto Histopaque 1119). Cells were then washed twice with Roswell Park Memorial Institute medium (RPMI) at $200 \mathrm{Xg}$ for $10 \mathrm{~min}$ before being quantified. Viability of the cells was $>99 \%$ viable when assessed by Trypan blue exclusion.

\section{Neutrophils culture}

Neutrophils (1×10\%/well) from healthy donors were cultured in 24-well plates, in presence of medium only, or Lipopolysaccharide (LPS) (10 ng/ $\mathrm{mL}), \mathrm{N}$-formyl-methionine-leucine-phenylalanine (fMLP) $(1.5 \mu \mathrm{M})$ in presence or absence of different concentrations of budlein $A(1,10$ or $100 \mu \mathrm{M})$ or dexamethasone $(100 \mu \mathrm{M})$.

\section{T cell culture and proliferation assays}

Carboxyfluorescein Succinimidyl Ester (CFSE) (Invitrogen - Eugene, OR, USA) labeled-PBMC ( $1 \times 10^{6} /$ well) from healthy donors were cultured in 24well plates, in the presence of phytohaemagglutinin (PHA) $(1 \mu \mathrm{g} / \mathrm{ml})(\mathrm{SIGMA})$, or in presence or absence of different concentrations of budlein $A(1,10$, or $100 \mu \mathrm{M})$ or dexamethasone $(100 \mu \mathrm{M})$, at $37^{\circ} \mathrm{C}$ and $5 \% \mathrm{CO}_{2}$. On day 4 , the cells were harvested and the proliferative response of $T$ cells was assessed by measuring the CFSE dilution using flow cytometry. The proliferation of $T$ cells was characterized by sequential halving of CFSE fluorescence, generating equally spaced peaks on a logarithmic scale. The data represents the percentage of proliferation of $T$ cells. The cell acquisition was performed on a FACSort flow cytometer using CellQuest software (BD Biosciencess - San Diego, CA, USA).

\section{Myeloperoxidase activity}

Myeloperoxidase (MPO) activity was determined by enzymatic reaction, as previously described ${ }^{26}$. Neutrophils were harvested after culture and centrifuged at $350 \mathrm{Xg}$ for $15 \mathrm{~min}$, and the pellet was frozen at $-20^{\circ} \mathrm{C}$. The pellet was then liquefied and centrifuged twice at $10,000 \mathrm{Xg}$ for $15 \mathrm{~min}$ at $4^{\circ} \mathrm{C}$. The MPO activity in the suspended pellet was assayed by measuring the change in absorbance at $450 \mathrm{~nm}$ using tetramethylbenzidine $(1.6 \mathrm{mM})$ and $\mathrm{H}_{2} \mathrm{O}_{2}$ (0.5 mM) (BD Biosciences).

\section{Cytokine assays}

Interleukin (IL)-2, IL-6, CXCL8, IL-10, IL-12, Transforming Growth Factor (TGF)- $\beta$, and Interferon (IFN)- $\gamma$ levels were measured using ELISA kits (BD Biosciences or R\&D Systems - Minneapolis, MN, USA), according to the manufacturer's instructions.

\section{Apoptosis}

Cells were harvested after culture and the viability was analyzed by flow cytometry, as previously described ${ }^{26}$. The percentage of apoptotic cells was calculated from the proportion of neutrophils, as well as lymphocyte positivity for Annexin- V-FITC or propidium iodide (ApoScreen ${ }^{\mathrm{TM}}$ Annexin V-FITC kit, SouthernBiotech - Birmingham, $A L, U S A)$, in relation to total number of cells ${ }^{26}$.

\section{Statistical analysis}

Values are presented as mean \pm SEM. Statistical analysis was performed using ANOVA followed 

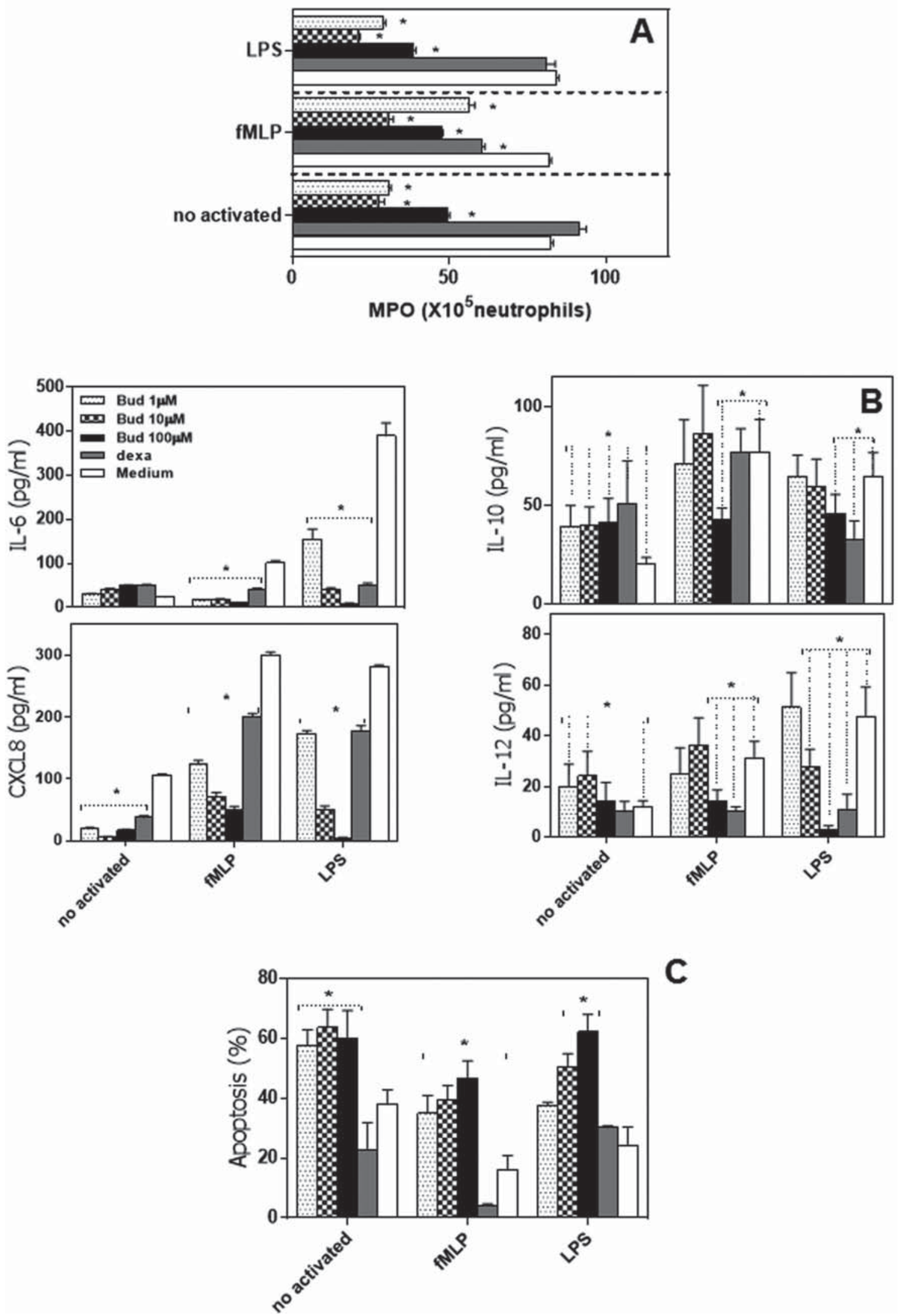

Figure 1- Budlein A negatively regulated the neutrophil activation to fMLP and LPS. Neutrophils from healthy controls were cultured with medium only or budlein $\mathrm{A}(1 \mu \mathrm{M}, 10 \mu \mathrm{M}$, or $100 \mu \mathrm{M})$, dexamethasone $(100 \mu \mathrm{M})$, budlein plus fMLP, or budlein plus LPS. (A) Analysis of myeloperoxidase activity (MPO). B) IL-6, CXCL8, IL-10, and IL-12 production were analyzed by ELISA. (C) Flow cytometric analysis of apoptosis. The bars represent the mean \pm SEM for each volunteer individually tested. * $p<0.05$ 
by the Tukey's multiple comparison test (INSTAT Software; GraphPad Prism, La Jolla, CA, USA). All values were considered significant when $p \leq 0.05$.

\section{RESULTS}

Budlein A inhibits MPO activity, cytokine production, and induces neutrophil apoptosis

To evaluate the anti-inflammatory effects of budlein $A$ on neutrophils, cells were stimulated with fMLP or LPS in presence or absence of budlein A ( 1 , 10 , or $100 \mu \mathrm{M}$ ) or dexamethasone (positive control), and the myeloperoxidase (MPO) activity, IL-6, CXCL8, IL-10, and IL-12 production and apoptosis were analyzed. Consistent with prior observation ${ }^{27}$, budlein $A$ inhibited in a concentration-dependent manner the MPO activity by LPS-stimulatedneutrophils (Fig. 1A). Our results also indicate that at a concentration of 10 and $100 \mu \mathrm{M}$, budlein A reduced MPO activity by $\mathrm{fMLP}$-stimulated neutrophils (Figure $1 \mathrm{~A}$ ).

Because neutrophils appear to be important producers of cytokines during innate immune response and cytokines are important mediators of the inflammatory process, we assessed whether budlein A affects cytokine and chemokine production by neutrophils (Figure $1 B$ ). Unstimulated neutrophils produced basal levels of IL-6, IL-10, CXCL8, and IL-12. Budlein A decreased CXCL8 production, induced IL-10 production and did not alter IL-12 and IL- 6 production by unstimulated neutrophils. After $21 \mathrm{~h}$ of culture, LPS and fMLP enhanced IL-6, CXCL8, IL-12, and IL-10 production by human neutrophils. In contrast, budlein $A$ inhibited in a concentration-dependent manner IL- 6 and CXCL8 production by fMLP and LPSstimulated neutrophils. Moreover, budlein A, at only $100 \mu \mathrm{M}$ concentration, inhibited IL-10 and IL-12 production by fMLP and LPS-stimulated-neutrophils, while at $10 \mu \mathrm{M}$ it inhibited IL-12 production by LPS-activated neutrophils (Figure 1B). To verify whether the results were the consequence of cell death, we analyzed the apoptosis of neutrophils. Our data showed that only budlein $A$ at $100 \mu \mathrm{M}$ concentration significantly induced neutrophil apoptosis (33.19 $\pm 5.70 \%)$, similar to that observed after culture with dexamethasone $(22.83 \pm 0.51 \%)$ (Figure 1C). Similar results were observed when fMLP or LPS-stimulated neutrophils were treated with budlein $A(100 \mu M)$ (Figure $1 C)$.

\section{Budlein A inhibited T cell proliferation}

To determine the anti-inflammatory effects of budlein $A$ on lymphocytes, cells were cultured with PHA in presence or absence of budlein $A$ $(1,10$, or $100 \mu \mathrm{M})$ or dexamethasone (positive control), and proliferation, IL-2, IL-10, IFN- $\gamma$, and
TGF- $\beta$ production and apoptosis were analyzed. Lymphocytes exhibit proliferative response after PHA stimulation, and the addition of budlein A (100 $\mu M$ ) significantly reduced $T$ cell proliferation (Figure $2 \mathrm{~A}$ ). These results indicate that budlein $\mathrm{A}$ interferes with PHA-induced $\mathrm{T}$ cell proliferation. Regarding cytokine production, the results evidenced that budlein $A(100 \mu \mathrm{M})$ decreased IFN- $\gamma$, IL-2, IL10 , and TGF- $\beta$ production by PHA-stimulated lymphocytes, with similar effects to dexamethasone (Figure 2B).

Since budlein A negatively modulates the secretion of cytokines by PHA-stimulated lymphocytes, and this could be a consequence of cell death, their apoptosis was evaluated (Figure 2C). We found that budlein $A(1,10$, or $100 \mu \mathrm{M})$ does not induce lymphocyte apoptosis (Figure 2C). These data indicate that budlein A exerts an important role against lymphocytes' activation, but it did not induce cell death.

\section{SCUSSI ON}

Although budlein $A$ has been described as presenting anti-inflammatory and anti-nociceptive activity ${ }^{1,7,27}$, specific effects of this compound on immune cells are lacking. In the present study, we demonstrated that budlein $A$ inhibit neutrophils activation and induce cell death, but, despite also inhibiting lymphocyte activation, it did not induce lymphocyte death.

Budlein A inhibited in a concentration-dependent manner the release of biochemical mediators by neutrophils, and this activity could possibly reduce tissue damage caused by the enzyme ${ }^{24,28}$. The MPO activity can be deleterious to the host, and it has been implicated in the pathogenesis of many inflammatory diseases ${ }^{21}$. Myeloperoxidase has also been established as a risk factor for many forms of cancer via its ability to damage/mutate cellular DNA or indirectly via its pro-inflammatory role ${ }^{9,21}$. The anti-inflammatory activity of $\mathrm{SL}$ is mediated via the inhibition of nuclear factor-kappa B (NF$\mathrm{KB}$ ) by the alkylation of the cysteine residue in the p65 subunit ${ }^{18}$, impairing its activation and the consequent production of inflammatory mediators ${ }^{15,17}$

Another important effect of budlein $A$ on neutrophils shown in this study was the inhibition of IL-6, CXCL-8, IL-10, and IL-12 production. Proinflammatory cytokines (IL-6, CXCL8, and IL-12) are involved in the initiation and amplification of the immune response, and anti-inflammatory cytokines modulate the late events to control the immune response ${ }^{23}$. The imbalance between pro- and antiinflammatory cytokine activities favors chronic inflammation and autoimmune diseases $8,20,23$. Imbalance in the production of inflammatory 


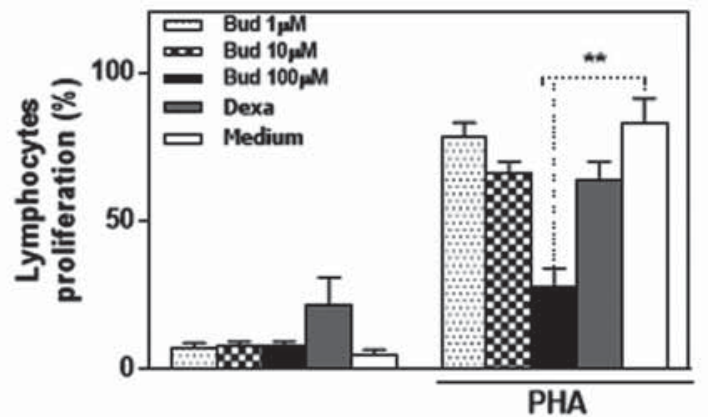

A
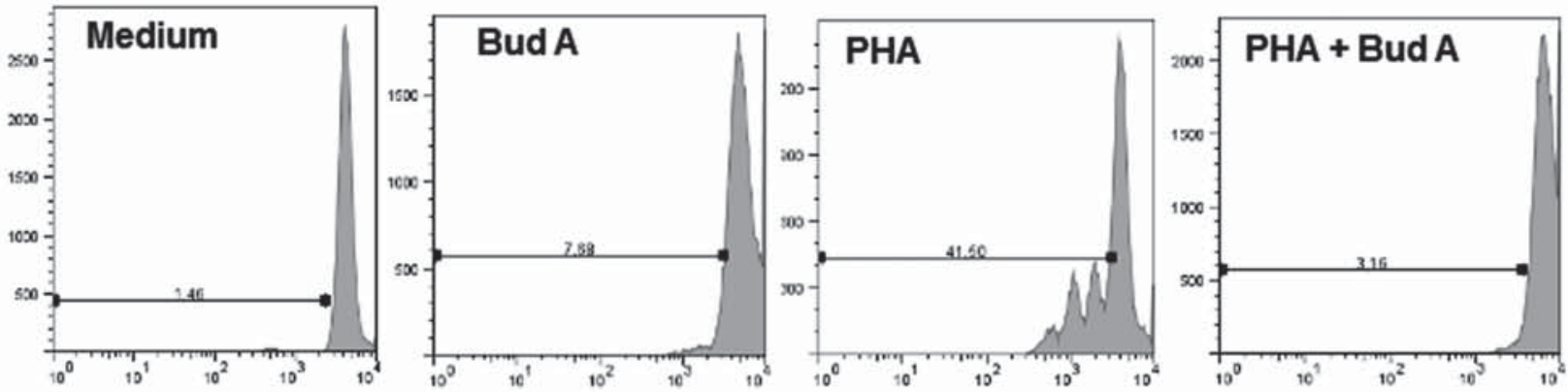

\section{CFSE}
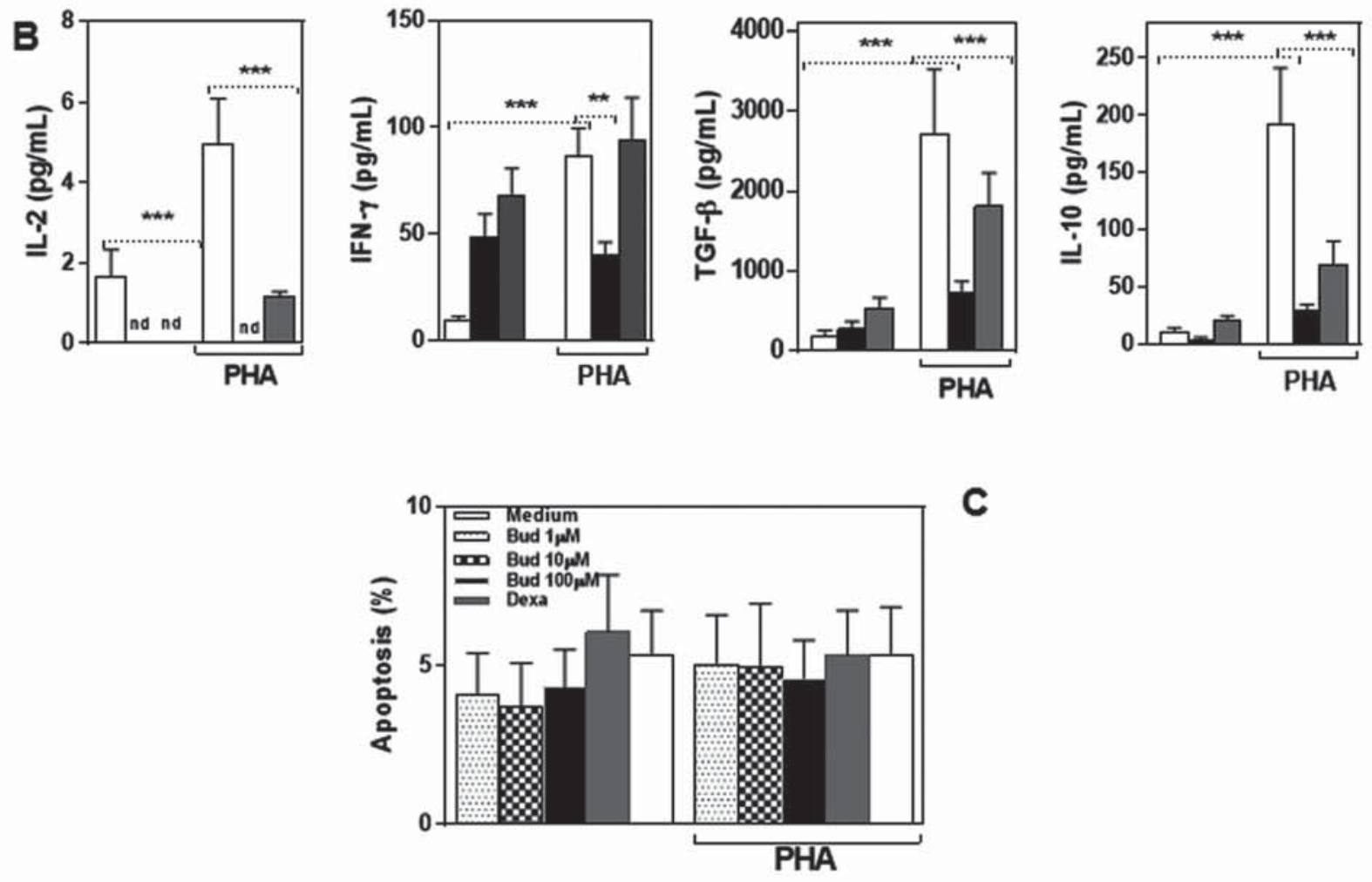

C

Figure 2- Budlein A inhibited T cell proliferation. (A) Flow cytometric analysis of proliferative response of PBMC cultured with Budlein A, dexamethasone, and PHA (1.5 mM) for 96 h. (B) IL-2, IFN-gamma, TGF-beta, and IL10 concentration in supernatant were analyzed by ELISA. (C) Flow cytometric analysis of apoptosis. The bars represent the mean \pm SEM of values obtained for each subject individually tested. ${ }^{*} p<0.05,{ }^{* *} p<0.01,{ }^{* * *} p<0.001$ was considered statistically significant when compared with the medium 


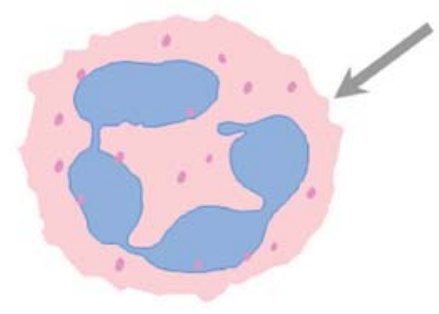

Neutrophil

\begin{tabular}{|} 
dose dependent effect \\
$\downarrow$ MPO activity \\
$\downarrow$ secretion of cytokines/chemokines \\
$\downarrow$ viability
\end{tabular}
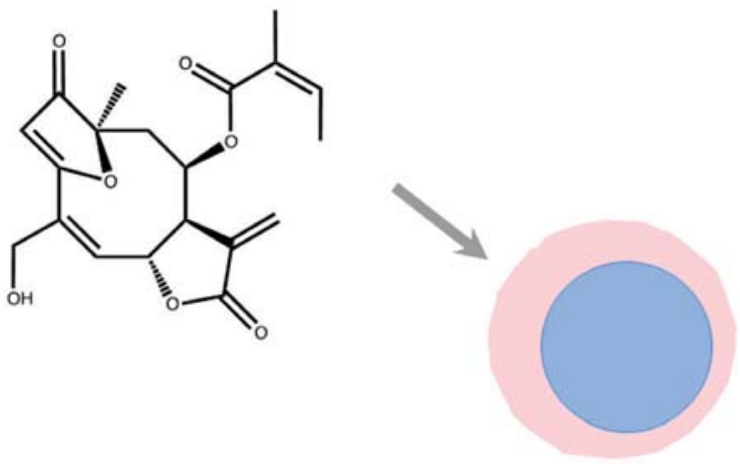

Lymphocyte

\begin{tabular}{|c|}
\hline dose dependent effect \\
$\downarrow$ proliferation \\
$\downarrow$ secretion of cytokines/growth factors \\
maintaining viability
\end{tabular}

Figure 3- Graphical abstract showing effects of Budlein A on human neutrophils and lymphocytes

cytokines may allow a local inflammation to become an uncontrolled systemic inflammatory response $8,20,21$.

Because low cytokine production might have occurred as a consequence of cytotoxic effects exerted by budlein $A$, we analyzed the apoptosis of human neutrophils. Only budlein $A$, at the 100 $\mu \mathrm{M}$ concentration, induces neutrophils apoptosis. The death of neutrophils observed in this study may be due to the absence of growth factors, particularly CXCL8, since budlein $A$, as well as other sesquiterpenes, inhibits activation of NF$\mathrm{KB}$ and the production of cytokines related to neutrophil survival ${ }^{1,23}$. In fact, $1 \mu \mathrm{M}$ of budlein $A$ did not significantly induce neutrophil apoptosis, but it did not significantly inhibit the production of CXCL8 either. Another possible explanation could be a direct influence of the substance in neutrophil survival. Death of neutrophil induced by budlein $A$ could be harmful to immune response, pathogen clearance, and tissue repair ${ }^{24,25}$. Neutrophils are involved with different inflammatory diseases and their apoptosis might generate an anti-inflammatory microenvironment as well ${ }^{26}$. The precise regulation of neutrophil apoptosis is essential for resolution of inflammation, since this prevents the release of toxic intracellular components that can damage healthy tissues ${ }^{10,12,19,26}$. Thus, anti-inflammatory agents that induced neutrophil apoptosis would only be helpful in some chronic inflammatory diseases, since these diseases present persistent inflammatory mediators avoiding their resolution ${ }^{12,26,27}$. A plethora of those inflammatory mediators (i.e., the reactive oxygen species or neutrophil extracellular traps) is produced by viable neutrophils ${ }^{13,28}$. These mediators could influence autoimmune diseases at different levels and by different ways, such as directly through the inhibition of cytokines, modulating their production or damaging surrounding tissues ${ }^{14,28}$. Several diseases seem to be affected by activated neutrophils, including rheumatoid arthritis (RA) and systemic lupus erythematosus (SLE) 13,14,28. Hence, reduced numbers of activated neutrophils might generate a protected microenvironment from dramatic consequences from their uncontrolled inflammation ${ }^{29}$.

Interestingly, despite previous studies having shown that high concentrations of sesquiterpene lactones induced apoptosis of $\mathrm{PBMC}^{30}$, we did not find any significant change in lymphocyte death using three different concentrations of budlein $A$. Budlein $A$ at $100 \mu \mathrm{M}$ significantly inhibited PHAproliferation of lymphocytes as well as IFN- $y$, IL-2, IL-10, and TGF- $\beta$ production. Other studies have described a significant inhibition of lymphocyte proliferation via other sesquiterpenes; however, the viability rate of the cells had not been evaluated ${ }^{23}$. Here, inhibition of lymphocyte proliferation might be a consequence of undetectable levels of IL2, an important cytokine inducing lymphocyte proliferation. Thus, budlein A might be an important inhibitor of uncontrolled lymphocyte proliferation without inducing their apoptosis. Such situation would facilitate their use in diseases without directly affecting their survival.

Therefore, our results also show that budlein A induced apoptosis of neutrophils but not lymphocytes, and indicate that budlein A shows distinct immunomodulatory effects on immune cells (Figure 3 ). 


\section{CONCLUSI ONS}

The anti-inflammatory activities mediated by budlein A reveal an important potential to the study of mechanisms of action and therapeutics ${ }^{1,5}$. In the present study, we demonstrated that budlein $A$ inhibits neutrophil activation and induces cell death, but, despite also inhibiting lymphocyte activation, it did not induce lymphocyte death. Further studies are necessary to understand the significance of this compound in the treatment of chronic inflammatory diseases. It will be of interest to evaluate how the balance between these positive and negative effects could be regulated during the course of the immune response.

\section{ACKNOWLEDGEMENTS}

The authors would like to thank FAPESP São Paulo Research Foundation for the financial support (2008/57149-8). The authors were supported by FAPESP [scholarship granted to C.D.K (2008/09554-0) and M.S. (2008/039317)] and CNPq - National Council for Scientific and Technological Development (scholarship granted to F. B. Da C., and A.P.C.).

\section{REFERENCES}

1- Arakawa NS, Schorr K, Ambrósio SR, Merfort I, Costa FB. Further sesquiterpene lactones from Viguiera robusta and the potential anti-inflammatory activity of a heliangolide: inhibition of human neutrophil elastase release. Z Naturforsch C. 2008;6:533-8.

2- Calixto JB, Campos MM, Otuki MF, Santos AR. Anti-inflammatory compounds of plant origin. Part II. Modulation of proinflammatory cytokines, chemokines and adhesion molecules. Planta Med. 2004;70:93-103.

3- Cho JY, Baik KU, Jung JH, Park MH. In vitro anti-inflammatory effects of cynaropicrin, a sesquiterpene lactone, from Saussurea lappa. Eur J Pharmacol. 2000;398:399-407.

4- Ciraci C, Janczy JR, Sutterwala FS, Cassel SL. Control of innate and adaptive immunity by the inflammasome. Microbes Infect. 2012; 14:1263-70.

5- Costa FB, Schorr K, Arakawa NS, Schilling EE, Sprin GO. Infraspecific variation in the chemistry of glandular trichomes of two Brazilian Viguiera species (Heliantheae; Asteraceae). J. Braz. Chem. Soc. 2001;12:403-7.

6- De la Fuente $H$, Cibrián D, Sánchez-Madrid F. Immunoregulatory molecules are master regulators of inflammation during the immune response. FEBS Lett. 2012;586:2897-905.

7- De Vivar AR, Guerrero C, Diaz E, Bratoeff EA, Jiménez L. The germacranolides of Viguiera buddleiaeformis structures of budlein-A and -B. Phytochemistry. 1976;15:525-9.

8- Demoruelle MK, Deane KD, Holers VM. When and where does inflammation begin in rheumatoid arthritis? Curr Opin Rheumatol. 2014;26:64-71.

9- Federico A, Morgillo F, Tuccillo C, Ciardiello F, Loguercio C. Chronic inflammation and oxidative stress in human carcinogenesis. Int J Cancer. 2007;121:2381-6.

10- Freire MO, Van Dyke TE. Natural resolution of inflammation. Periodontol 2000. 2013;63:149-64.
11- Geetha BS, Nair MS, Latha PG, Remani P. Sesquiterpene lactones isolated from Elephantopus scaber L. inhibits human Iymphocyte proliferation and the growth of tumour cell lines and induces apoptosis in vitro. J Biomed Biotechnol. 2012;2012:721285

12- Getts DR, McCarthy DP, Miller SD. Exploiting apoptosis for therapeutic tolerance induction. J. Immunol. 2013;191:5341-6. 13- Huang X, Li J, Dorta-Estremera S, Di Domizio J, Anthony SM, Watowich SS, et al. Neutrophils regulate humoral autoimmunity by restricting interferon- $y$ production via the generation of reactive oxygen species. Cell Rep. 2015;12:1120-32.

14- Kaplan MJ. Role of neutrophils in systemic autoimmune diseases. Arthritis Res Ther. 2013;15:219.

15- Lawrence T. The nuclear factor NF-kappa B pathway in inflammation. Cold Spring Harb Perspect Biol. 2009;1:1-10.

16- Lee HJ, Kim NY, Jang MK, Son HJ, Kim KM, Sohn DH, et al. A sesquiterpene, dehydrocostus lactone, inhibits the expression of inducible nitric oxide synthase and TNF-alpha in LPS-activated macrophages. Planta Med. 1999;65:104-8.

17- Lee HK, Song HE, Lee HB, Kim CS, Koketsu M, Ngan LT, et al. Growth inhibitory, bactericidal, and morphostructural effects of dehydrocostus lactone from Magnolia sieboldii leaves on antibioticsusceptible and -resistant strains of Helicobacter pylori. PLoS One. 2014;9:e95530.

18- Lyss G, Knorre A, Schmidt TJ, Pahl HL, Merfort I. The anti-inflammatory sesquiterpene lactone helenalin inhibits the transcription factor NF-kappa B by directly targeting p65. J Biol Chem. 1998;273:33508-16.

19- McCracken JM, Allen LA. Regulation of human neutrophil apoptosis and lifespan in health and disease. J Cell Death. 2014;7:15-23.

20- McInnes IB, Schett G. Cytokines in the pathogenesis of rheumatoid arthritis. Nat Rev Immunol. 2007;7:429-42.

21- Mika D, Guruvayoorappan C. Myeloperoxidase: the yin and yang in tumour progression. J Exp Ther Oncol. 2011;9:93-100. 22- Nicolete R, Arakawa NS, Rius C, Nomizo A, Jose PJ, Costa FB, et al. Budlein A from Viguiera robusta inhibits leukocyte-endothelial cell interactions, adhesion molecule expression and inflammatory mediators release. Phytomedicine. 2009;16:904-15.

23- Perez DA, Vago JP, Athayde RM, Reis AC, Teixeira MM, Sousa LP, et al. Switching off key signaling survival molecules to switch on the resolution of inflammation. Mediators Inflamm. 2014:2014:829851.

24- Rijken F, Bruijnzeel-Koomen CA. Photoaged skin: the role of neutrophils, preventive measures, and potential pharmacological targets. Clin Pharmacol Ther. 2011;89;120-4.

25- Smith CK, Kaplan MJ. The role of neutrophils in the pathogenesis of systemic lupus erythematosus. Curr. Opin. Rheumatol. 2015;27:448-53.

26- Tessarolli V, Gasparoto TH, Lima HR, Figueira EA, Garlet TP, Torres SA, et al. Absence of TLR2 influences survival of neutrophils after infection with Candida albicans. Med Mycol. 2010;48:129-40. 27- Valério DA, Cunha TM, Arakawa NS, Lemos HP, Costa FB, Parada CA, et al. Anti-inflammatory and analgesic effects of the sesquiterpene lactone budlein $A$ in mice: inhibition of cytokine production-dependent mechanism. Eur J Pharmacol. 2007; 562:155-63.

28- Witko-Sarsat V, Rieu P, Descamps-Latscha B, Lesavre P, Halbwachs-Mecarelli L. Neutrophils: molecules, functions and pathophysiological aspects. Lab Invest. 2000;80:617-53.

29- Yu Y, Koehn CD, Yue Y, Li S, Thiele GM, Hearth-Holmes MP, et al. Celastrol inhibits inflammatory stimuli-induced neutrophil extracellular trap formation. Curr Mol Med. 2015;15:401-10 30- Ziaei A, Hoppstädter J, Kiemer AK, Ramezani M, Amirghofran $Z$, Diesel B. Inhibitory effects of teuclatriol, a sesquiterpene from Salvia mirzayanii, on nuclear factor- $\mathrm{kB}$ activation and expression of inflammatory mediators. J Ethnopharmacol. 2015;160:94-100. 